\title{
Fish consumption is a safe solution to increase the intake of long-chain $n-3$ fatty acids
}

\author{
Isabelle Sioen ${ }^{1,2, *}$, Stefaan De Henauw ${ }^{1,3}$, Wim Verbeke ${ }^{4}$, Frederik Verdonck ${ }^{5,6}$, \\ Jan L Willems ${ }^{1}$ and John Van Camp ${ }^{2}$ \\ 'Department of Public Health, Ghent University, UZ 2 Blok A, De Pintelaan 185, B-9000 Ghent, Belgium: \\ ${ }^{2}$ Department of Food Safety and Food Quality, Ghent University, Coupure Links 653, B-9000 Ghent, Belgium: \\ ${ }^{3}$ Department of Health Sciences, Vesalius, Hogeschool Gent, Keramiekstraat 80, B-9000 Ghent, Belgium: \\ ${ }^{4}$ Department of Agricultural Economics, Ghent University, Coupure Links 653, B-9000 Ghent, Belgium: \\ ${ }^{5}$ Department of Applied Mathematics, Biometrics \& Process Control (FV), Ghent University, Coupure Links 653, \\ B-9000 Ghent, Belgium: ${ }^{\circ}$ EURAS, Kortrijksesteenweg 302, B-9000 Ghent, Belgium
}

Submitted 10 April 2007: Accepted 24 October 2007: First published online 2 January 2008

\begin{abstract}
Objectives: Dietary intake of long-chain (LC) $n$ - 3 PUFA in developed countries is low compared with recommendations. Fish is naturally rich in LC $n-3$ PUFA, but is also a dietary source of heavy metals and organic pollutants. We investigated whether the recommendation for LC $n$-3 PUFA could be reached through fish consumption, without exceeding the provisional tolerable weekly intake of methylmercury (MeHg) and the tolerable weekly intake (TWI) of dioxin-like compounds. Also, the contribution of margarines enriched with LC n-3 PUFA was assessed.

Design: Published nutrient and contaminant data were used in a probabilistic model to calculate the simultaneous nutrient and contaminant intake for different fish consumption scenarios.

Results: The Belgian recommendation for EPA + DHA $(0 \cdot 3 \%$ of total energy intake) can be reached by consuming fatty fish a minimum of twice a week, or by varying between lean and fatty fish a minimum of three times a week. At this fish consumption level, MeHg intake is not an issue of toxicological concern. The intake of dioxin-like compounds approximates the TWI when consuming fatty fish more than twice a week, this being a potential toxicological risk because other food items also contribute to the weekly intake of dioxin-like compounds. Use of margarine enriched with LC $n$-3 PUFA can help to increase LC $n-3$ intake, on average by $159 \mathrm{mg} / \mathrm{d}$.

Conclusions: Combination of regular fish consumption (twice a week) with important contribution of fatty fish species, in combination with regular consumption of margarine enriched with EPA + DHA, can be advised to achieve the recommendation for LC $n-3$ intake.
\end{abstract}

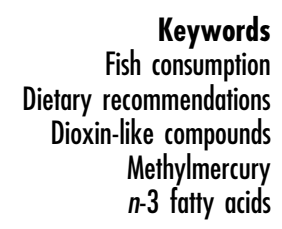

Keywords ietary recommendations Methylmercury $n-3$ fatty acids
Fundamental, clinical and epidemiological research has demonstrated the potential role of long-chain (LC) $n-3$ PUFA from the diet in the prevention of several diseases, in particular $\mathrm{CVD}^{(1-6)}$. Fish and other seafood are the richest natural dietary source of these LC $n-3$ PUFA, in particular EPA and DHA. The knowledge about the beneficial effects of LC $n-3$ PUFA has led in many countries to the formulation of dietary recommendations to achieve an adequate intake. In Belgium, the country under consideration in the present paper, such recommendations have been in place since $2003^{(7)}$.

Recent research shows that the current LC $n-3$ PUFA intake is inadequate in different subgroups of the Belgian population compared with the Belgian recommendation, which is $0.3 \%$ of the total energy intake ${ }^{(8-10)}$. Similar findings have been reported for other countries, e.g. Germany ${ }^{(11)}$, the $\mathrm{UK}^{(12)}$ and the USA ${ }^{(13,14)}$. Based on these results, it is reported that a modest increase in LC $n$-3 PUFA intake would have important and beneficial public health outcomes ${ }^{(14)}$. Increased fish consumption is suggested as a possible strategy to increase LC $n-3$ PUFA intakes in order to bridge the gap between current intakes and recommendations.

However, at the same time, fish and other seafood are a source of persistent chemical contaminants that accumulate in the marine environment. Non-carcinogenic 
(e.g. methylmercury $(\mathrm{MeHg})$ ) and carcinogenic (e.g. dioxins and polychlorinated biphenyl ethers (PCB)) contaminants accumulate in the marine food chain by bioaccumulation and biomagnification ${ }^{(15)}$. As a result, increased fish consumption aimed to achieve an adequate LC $n$-3 PUFA intake may simultaneously increase the intake of contaminants to levels of toxicological concern. Chronic exposure to $\mathrm{Hg}$ affects the central nervous system $^{(16)}$ and exposure to dioxin-like compounds causes dermal toxicity, immunotoxicity, carcinogenicity, reproductive and developmental toxicity, and disruption of endocrine functions ${ }^{(17)}$. On the other hand, consumers decreasing their fish intake in order to avoid contaminant exposure may be incurring an inadequate intake of LC $n$-3 PUFA $^{(18)}$.

The present study investigated whether the recommended intake of LC $n-3$ PUFA can be reached by fish consumption only, without exceeding the provisional tolerable weekly intake (PTWI) of MeHg and the tolerable weekly intake (TWI) of dioxin-like compounds. The rationale for focusing on $\mathrm{MeHg}$ was that fish is the most important dietary source of $\mathrm{Hg}$ in the human food chain. The selection of dioxin-like compounds was motivated by the fact that fish has a higher concentration of dioxinlike compounds than other food items. Since dioxin-like compounds are lipophilic, their concentration in fish is highly related to the fat content of the fish ${ }^{(19)}$. Most of the previously published quantitative analyses of the benefits and risks of fish consumption are limited as they were restricted to salmon ${ }^{(20-22)}$ or restricted to $\mathrm{Hg}$ as considered contaminant ${ }^{(18,23,24)}$. In the present study, a quantitative assessment was performed to calculate the simultaneous intake of LC $n$-3 PUFA and multiple contaminants. Moreover, a combination of fish consumption and margarine enriched with LC $n-3$ PUFA was examined. An analysis of the ensuing health risk was performed and fish consumption recommendations were formulated by balancing the associated risks and benefits to maximize public health.

\section{Materials and methods}

The quantitative assessment was performed on the basis of hypothetical scenario analyses. The elaboration and implementation of the different scenarios are presented in Fig. 1. Three consumption scenarios were built starting from the current Belgian fish consumption pattern (based on the seven most consumed species). This consumption pattern was artificially changed in two ways to end up with three consumption scenarios: (i) the current consumption pattern: (ii) increasing the consumption of fatty fish up to $50 \%$ of the total fish consumed; and (iii) replacing all lean fish species by fatty fish species. Next, three sub-scenarios were added per consumption scenario: (i) consuming fish only once a week; (ii) consuming fish twice a week; and (iii) consuming fish three times a week.

\section{Nutrient and contaminant data}

The nutrient and contaminant concentrations used in the present study originated from two extensive, newly compiled databases containing published data on nutrient and contaminant concentrations in different fish species relevant for Belgian consumption ${ }^{(19,25)}$. The sum of EPA and DHA concentrations (EPA + DHA; expressed in $\mathrm{mg} / \mathrm{g}$ fish) was considered as one aggregate nutrient (LC $n$-3 PUFA). In addition, the following contaminants were included: $\mathrm{MeHg}$ (expressed in $\mathrm{ng} / \mathrm{g}$ fish), dioxin-like PCB (dlPCB; congeners 77, 81, 126, 169, 105, 114, 118, 123, 156, 157, 167, 189; expressed in pg WHO-TEQ/g fish), dioxins plus furans (referred to below as PCDD/F, i.e. the sum of seven polychlorinated dibenzo- $p$-dioxin (PCDD) congeners and ten polychlorinated dibenzofuran (PCDF) congeners; expressed in pg WHO-TEQ/g fish) and total dioxin-like compounds (referred below to as total TEQ (totTEQ), i.e. the sum of all dioxin-like compounds $=12 \mathrm{dlPCB}$ congeners $+17 \mathrm{PCDD} / \mathrm{F}$ congeners; expressed in $\mathrm{pg}$ WHO-TEQ/g fish).

Considering the concentrations of dioxin-like compounds in salmon and herring, contaminant concentrations measured in Baltic salmon and herring were excluded from the analyses; they risk having totTEQ concentrations above European Union (EU) limits because the Baltic Sea has been contaminated for many years by dioxin-like compounds from emissions of paper and metal industry plants and waste incineration plants $^{(26-28)}$. The European Commission set a maximum allowable concentration in edible parts of fish of $4 \mathrm{pg}$ WHO-TEQ/g fresh weight for PCDD/F and $8 \mathrm{pg}$ WHO$\mathrm{TEQ} / \mathrm{g}$ fresh weight for totTEQ (except eel may contain up to $12 \mathrm{pg}$ WHO-TEQ/g fresh weight $)^{(29)}$. Only Finland and Sweden had an exemption order until the end of 2006 to place fish from the Baltic region with concentrations above this limit on the domestic market, but they were not allowed to export it ${ }^{(26,27)}$. The presence of Baltic fish on the Belgian market is, therefore, considered negligible.

Table 1 shows the median, the 5th and the 95th percentile of the species-specific ratio of the EPA + DHA concentration to the $\mathrm{MeHg}$ or totTEQ concentration: the higher the ratio, the higher the nutrient concentration relative to the contaminant concentration. The data illustrate that for some species the distribution of the ratio is very wide and skewed to the right, e.g. (EPA+ DHA):totTEQ for tuna and salmon.

\section{Consumption and body weight data}

The current fish species consumption pattern on which the scenarios were built took into account the seven most consumed fish species, determined through the 


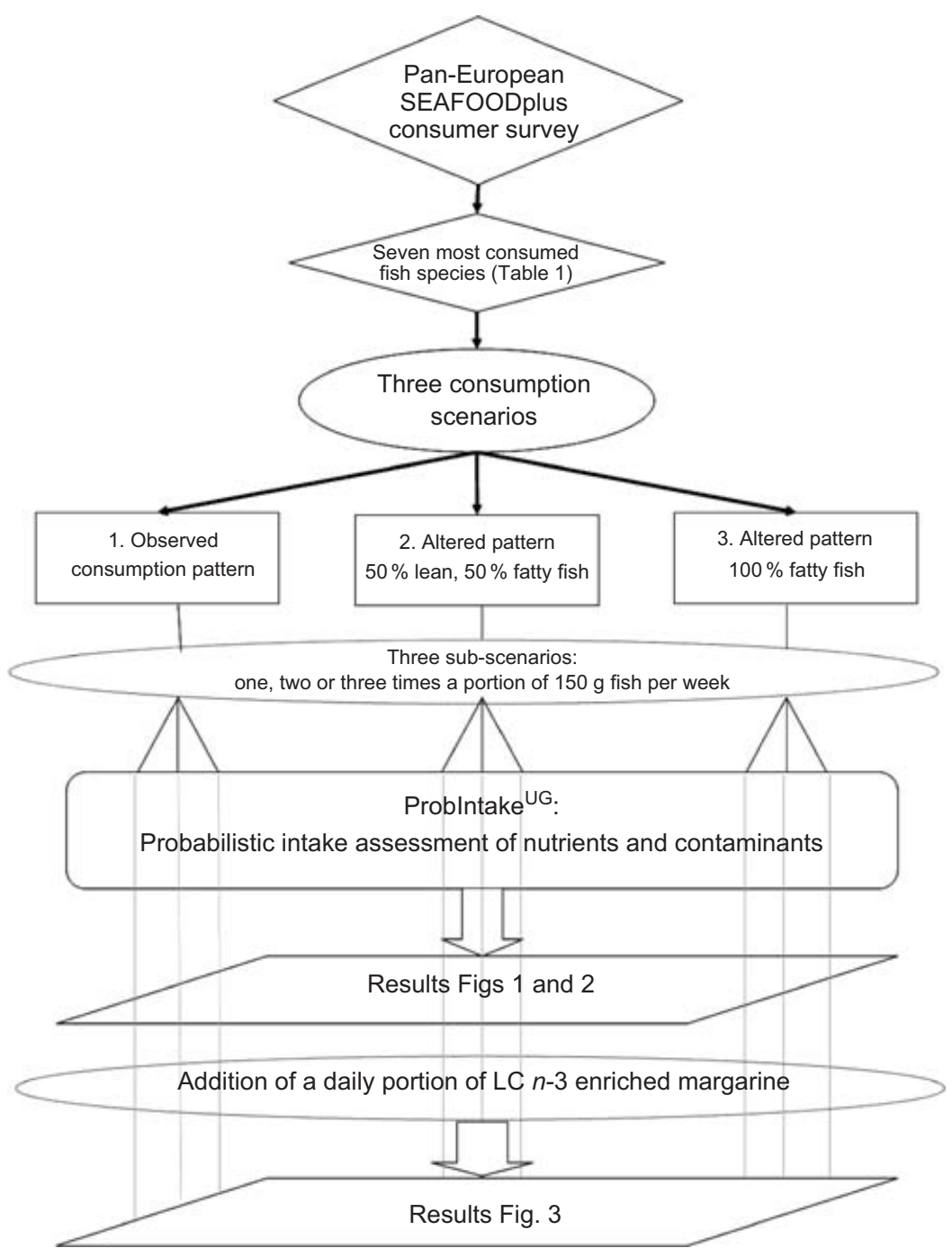

Fig. 1 Scheme of the elaboration and implementation of the different scenarios

Table 1 Contribution of the seven different fish species (\%) to the total fish consumption for the three consumption scenarios, as well as the concentration ratios of (EPA + DHA) to methylmercury (MeHg) or total dioxin-like compounds (totTEQ)

\begin{tabular}{|c|c|c|c|c|c|c|c|}
\hline \multirow[b]{3}{*}{ Species } & \multirow{2}{*}{\multicolumn{3}{|c|}{ Contribution to total fish consumption (\%) }} & \multicolumn{4}{|c|}{ Concentration ratio } \\
\hline & & & & \multicolumn{2}{|c|}{$(\mathrm{EPA}+\mathrm{DHA}): \mathrm{MeHg}\left(\times 10^{-3}\right)$} & \multicolumn{2}{|c|}{$(E P A+D H A): t o t T E Q\left(\times 10^{-6}\right)$} \\
\hline & $\begin{array}{l}\text { Current consumption } \\
\text { pattern }\end{array}$ & $\begin{array}{c}50 \% \text { lean } \\
\& 50 \% \text { fatty fish }\end{array}$ & $\begin{array}{l}\text { Only fatty } \\
\text { fish }\end{array}$ & Median & P5, P95 & Median & P5, P95 \\
\hline Cod & $24 \cdot 7$ & $19 \cdot 0$ & $0 \cdot 0$ & 0.06 & $0.03,0.11$ & $18 \cdot 89$ & $4 \cdot 04,59 \cdot 13$ \\
\hline Tuna & $19 \cdot 1$ & $14 \cdot 7$ & 0.0 & 0.02 & $0 \cdot 00,0 \cdot 12$ & $2 \cdot 39$ & $0 \cdot 19,42 \cdot 38$ \\
\hline Alaska pollock & $13 \cdot 6$ & $10 \cdot 5$ & 0.0 & $0 \cdot 11$ & $0 \cdot 05,0.26$ & $13 \cdot 75$ & $5 \cdot 09,58 \cdot 74$ \\
\hline Plaice & $7 \cdot 4$ & $5 \cdot 7$ & 0.0 & $0 \cdot 16$ & $0.04,0.36$ & $5 \cdot 57$ & $1 \cdot 39,13 \cdot 98$ \\
\hline Total lean fish & $64 \cdot 9$ & $50 \cdot 0$ & 0.0 & & & & \\
\hline Atlantic salmon & $19 \cdot 7$ & $28 \cdot 0$ & $56 \cdot 0$ & 0.93 & $0.31,1.99$ & $8 \cdot 73$ & $2 \cdot 35,57 \cdot 64$ \\
\hline Herring & $8 \cdot 0$ & $11 \cdot 4$ & $22 \cdot 8$ & 0.45 & $0 \cdot 20,2 \cdot 06$ & 3.92 & $1 \cdot 20,9 \cdot 86$ \\
\hline Mackerel & $7 \cdot 4$ & $10 \cdot 6$ & $21 \cdot 1$ & 0.94 & $0 \cdot 31,2 \cdot 28$ & $10 \cdot 33$ & $5 \cdot 03,23 \cdot 05$ \\
\hline Total fatty fish & $35 \cdot 2$ & $50 \cdot 0$ & $100 \cdot 0$ & & & & \\
\hline
\end{tabular}

P5, 5th percentile; P95, 95th percentile.

pan-European SEAFOODplus consumer survey ${ }^{(30)}$. Table 1 shows that currently $65 \%$ of the total fish consumption in Belgium is composed of lean fish species ( $\leq 5 \%$ fat), with cod as the most important species. Salmon is the most consumed fatty fish $(>5 \%$ fat). From this first consumption pattern, two scenarios with an altered 
Table 2 Mean (SD) of the applied body weight distributions (based on representative Belgian data*)

\begin{tabular}{lccccc}
\hline & \multicolumn{4}{c}{ Body weight $(\mathrm{kg})$} \\
\cline { 2 - 3 } & \multicolumn{2}{c}{ Men } & & \multicolumn{2}{c}{ Women } \\
\cline { 2 - 3 } \cline { 5 - 6 } Age interval (years) & Mean & SD & & Mean & SD \\
\hline 30-39 & $77 \cdot 2$ & $11 \cdot 2$ & $62 \cdot 7$ & $10 \cdot 9$ \\
40-49 & $78 \cdot 9$ & $11 \cdot 5$ & $66 \cdot 7$ & $11 \cdot 7$ \\
50-59 & $77 \cdot 4$ & $11 \cdot 4$ & $69 \cdot 5$ & $11 \cdot 2$ \\
60-69 & $75 \cdot 3$ & $12 \cdot 3$ & & $69 \cdot 5$ & 11.9 \\
\hline
\end{tabular}

${ }^{\star}$ From references 31 and 32.

fatty/lean species share were constructed to end up with three different consumption patterns: (i) the current consumption pattern; (ii) increasing the contribution of fatty fish ( $>5 \%$ fat) consumption to $50 \%$ of the total fish consumption; and (iii) replacing all lean fish species ( $\leq 5 \%$ fat) by fatty fish. The contribution of the different species to the total fish consumption in the altered patterns was calculated proportionally to their contribution in the current pattern (Table 1).

For the intake assessment, a hypothetical population sample of 600 individuals was used (300 men, 300 women), equally divided over four different age classes (30-39 years; 40-49 years; 50-59 years; 60-69 years). Normal body weight distributions were applied per gender and age interval, based on available data for the Belgian population (BIRNH study ${ }^{(31,32)}$; Table 2 ). The number of 600 individuals was sufficient to lead to a good convergence of the intake results (results not shown here).

\section{Simulation model and probabilistic metbodology}

The following simulation model, combining speciesspecific fish consumption data with nutrient and contaminant concentration data, was used for the intake assessment:

$$
Y_{i}=\frac{\Sigma_{v} \Sigma_{t}\left(X_{v, i, t} C_{v}\right)}{t \cdot B W_{i}},
$$

where $Y_{i}$ is the average daily intake of individual $i$ per $\mathrm{kg}$ body weight (BW); $X_{v, i, t}$ is the amount (g) of fish species $v$ consumed by individual $i$ (with $B W_{i}$ ) at day $t(t=1, \ldots, T)$; and $C_{v}$ is the concentration of a specific nutrient/contaminant in fish species $v$. A probabilistic approach was applied for the simulations, taking into account the variability of the consumption, body weight and concentration data. For consumption, the variability was taken into account in a non-parametric way, i.e. by using the data as such. For the body weight and concentration data, the variability was taken into account in a parametric way, i.e. by using species- and compound-specific probability distributions fitted to the available concentration data, using the @Risk software package version 4.5 (Pallisade Corporation, Newfield, NY, USA).
Details about this latter procedure have been given previously $^{(19,25)}$.

To execute the simulations, a software module called ProbIntake ${ }^{U G}$ was applied (developed at Ghent University, Belgium). ProbIntake ${ }^{\mathrm{UG}}$ is applicable in the freely available software program $R^{\circledR}$ (R Foundation for Statistical Computing, Vienna, Austria) ${ }^{(33)}$. The simulation procedure in this program for each individual worked as follows: each single consumption data point was multiplied with a concentration data point. This multiplication was conducted for all consumed fish species and for all different compounds. Next, the assessed intakes per compound were enumerated and this sum was divided by the number of consumption days considered and by the individual's body weight. Finally, this procedure was repeated for all individuals. For the purpose of optimizing integration of the inter-species variability in the nutrient and contaminant concentrations during the intake assessment, it was assumed that consumers kept this consumption pattern for a whole year (52 weeks) to finally calculate the average daily intake over a long-term period.

\section{Evaluation of nutrient and contaminant intakes}

To evaluate population intakes of EPA plus DHA, an ad hoc reference value for EPA + DHA of $681 \mathrm{mg} / \mathrm{d}$ or $9.7 \mathrm{mg} / \mathrm{kg}$ BW per $\mathrm{d}$ was calculated starting from the existing Belgian recommendation equal to $0 \cdot 3 \%$ of the total energy intake ${ }^{(7)}$ and assuming a mean body weight of $70 \mathrm{~kg}$ and a mean energy intake of $8.56 \mathrm{MJ} / \mathrm{d}$ $(2046 \mathrm{kcal} / \mathrm{d})$, the latter based on the data of the most recent Belgian Food Consumption Survey (BFCS; 3245 individuals older than 15 years: 1623 women, 1622 men) ${ }^{(34)}$. Dividing the EPA + DHA reference value by the body weight was relevant in this study in order to express the reference values for nutrients and contaminants on the same scale. For MeHg, a PTWI of $1.6 \mu \mathrm{g} / \mathrm{kg} \mathrm{BW}$ per week $\left(0 \cdot 228 \mu \mathrm{g} / \mathrm{kg}\right.$ BW per d) is proposed ${ }^{(16)}$ and for dioxin-like compounds, the EU proposes $14 \mathrm{pg}$ WHOTEQ/kg BW per week (2 pg WHO-TEQ/kg BW per d) ${ }^{(28)}$.

To visualize the results, plots were created showing the intake of MeHg and totTEQ respectively, divided by their (P)TWI (expressed per day, i.e. tolerable daily intake (TDI)), in relation to the intake of EPA + DHA divided by the reference value $(9.7 \mathrm{mg} / \mathrm{kg}$ BW per $\mathrm{d})$. Consequently, the limit value for being at risk due to a too high contaminant intake or inadequate EPA + DHA intake is ' 1 ' on both axes. Extra reference lines were added on the plots: (i) at half of the TDI for totTEQ, to take into account that the human diet contains other sources of dioxin-like compounds; and (ii) at half of the reference value for $\mathrm{EPA}+\mathrm{DHA}$, since the Belgian recommendation for $\mathrm{EPA}+\mathrm{DHA}$ is high compared with other countries (see Discussion below). By adding these reference lines, different zones are obtained describing whether or not a sufficient amount of fish is consumed to meet 
the recommendation for EPA + DHA, with or without exceeding the contaminant TDI.

\section{Inclusion of long-chain n-3 PUFA-enriched margarine}

Currently, margarine enriched with EPA and DHA is commonly available on the Belgian market and is therefore also considered in the present study. The EPA and DHA concentration in enriched margarine varies a lot depending on the brand, but it varies also in time. The concentrations used here are obtained from the nutritional information mentioned on the product labels. A first brand available in Belgium claimed that their EPA + DHA-enriched margarine contains $5 \mathrm{mg}$ EPA + DHA/g margarine. A second brand indicated that the enriched margarine contains $7.5 \mathrm{mg}$ $\mathrm{EPA}+\mathrm{DHA} / \mathrm{g}$. A third manufacturer stated that its enriched variant of margarine contains $0.9 \mathrm{mg} \mathrm{DHA} / \mathrm{g}$. Belgian dietitians assessed that one slice of bread with a regular layer of margarine contains $5 \mathrm{~g}$ margarine ${ }^{(35)}$. Assuming a daily consumption of 4 to 7 slices of bread leads to a consumption of $20-35 \mathrm{~g}$ margarine daily and $100-262.5 \mathrm{mg}$ $\mathrm{EPA}+\mathrm{DHA}$ daily (using the two versions of margarine richest in $\mathrm{EPA}+\mathrm{DHA})$. The results of the most recent $\mathrm{BFCS}^{(34)}$ indicated that currently the mean daily consumption of culinary fats and margarines is $21 \cdot 2 \mathrm{~g}$ with an interquartile range of $6 \cdot 0-28 \cdot 6 \mathrm{~g}$. In the scenario analyses executed, it was assumed that all consumers would use the average daily amount of enriched margarine containing $7 \cdot 5 \mathrm{mg} \mathrm{EPA}+\mathrm{DHA} / \mathrm{g}$ margarine.

\section{Results}

\section{Fish as only source of EPA and DHA}

Table 3 and Figs 2 and 3 show the intake assessment results for the different scenarios and sub-scenarios. The results indicate that increasing the contribution of fatty fish will reduce the intake of MeHg. This could already be concluded based on comparison of the ratio (EPA + DHA):MeHg between lean and fatty fish species (Table 1). In contrast to MeHg, the intake of totTEQ increases when replacing lean by fatty fishes. This was expected given the lipophilic character of these contaminants. Simultaneously, increasing the contribution of fatty fish increases the intake of EPA + DHA. Some lean species also have a relative high (EPA + DHA): totTEQ ratio compared with other species, e.g. cod and pollock (Table 1), but the absolute concentration of EPA + DHA in these species is so low that an unrealistically large amount of these species would have to be eaten to achieve the recommended $\mathrm{EPA}+$ DHA intake.

Figures 2 and 3 provide scatter plots of EPA + DHA $v$. MeHg (Fig. 2) or totTEQ (Fig. 3) based on the results of the different consumption scenarios. Considering the $\mathrm{EPA}+\mathrm{DHA}$ intake, the results show that only a fish consumption pattern consisting of $50 \%$ lean fish and $50 \%$ fatty fish with a minimum consumption frequency of three times a week, or a fish consumption pattern consisting only of fatty species with a frequency of minimum twice a week, will lead to an adequate intake of EPA + DHA in respectively $48.0 \%$ and $92.5 \%$ of the population when using the Belgian recommendation and not taking into account other sources of these fatty acids. Figure 2 shows that none of the considered consumption scenarios will lead to the health-based guidance value for $\mathrm{MeHg}$ being exceeded, indicating that the $\mathrm{Hg}$ contamination of fish available on the Belgian market is not an issue of major concern. In contrast, Fig. 3 shows that when consuming a portion of fatty fish three times a week, the intake of dioxin-like compounds will approach the TDI and a certain proportion of the population (8.5\%) will exceed this value. Knowing that the human diet also contains other important sources of totTEQ, an intake of three portions fatty fish per week may be of toxicological concern. Therefore, consuming fatty fish more than twice a week is not recommended.

Table 3 Mean intake of different compounds for the three different fish consumption patterns and three different scenarios of consumption frequency

\begin{tabular}{|c|c|c|c|c|c|c|}
\hline & $\mathrm{MeHg}$ & iPCB & dIPCB & $\mathrm{PCDD} / \mathrm{F}$ & totTEQ & $\mathrm{EPA}+\mathrm{DHA}$ \\
\hline & \multicolumn{2}{|c|}{ (ng/kg BW per d) } & \multicolumn{3}{|c|}{ (pg WHO-TEQ/kg BW per d) } & $(\mathrm{mg} / \mathrm{kg} \mathrm{BW}$ per $\mathrm{d})$ \\
\hline & & & & $30 \mathrm{~g} /$ week & & \\
\hline Current pattern & $36 \cdot 19$ & $2 \cdot 63$ & 0.33 & 0.24 & $0 \cdot 40$ & $2 \cdot 66$ \\
\hline $50 \%$ lean and $50 \%$ fatty & $30 \cdot 40$ & $2 \cdot 88$ & 0.39 & $0 \cdot 30$ & 0.41 & $3 \cdot 22$ \\
\hline Only fatty fish & $8 \cdot 28$ & $3 \cdot 44$ & 0.54 & $\begin{array}{c}0.51 \\
0 \mathrm{~g} / \text { week }\end{array}$ & 0.58 & $5 \cdot 14$ \\
\hline Current pattern & $70 \cdot 01$ & $5 \cdot 26$ & 0.68 & 0.52 & $0 \cdot 79$ & $5 \cdot 32$ \\
\hline $50 \%$ lean and $50 \%$ fatty & 57.93 & $5 \cdot 70$ & $0 \cdot 77$ & 0.64 & $0 \cdot 82$ & $6 \cdot 43$ \\
\hline Only fatty fish & $16 \cdot 52$ & $6 \cdot 86$ & $1 \cdot 08$ & $\begin{array}{c}1 \cdot 08 \\
0 \mathrm{~g} / \text { week }\end{array}$ & $1 \cdot 14$ & $10 \cdot 28$ \\
\hline Current pattern & $106 \cdot 19$ & $7 \cdot 98$ & $1 \cdot 02$ & 0.73 & $1 \cdot 20$ & $8 \cdot 01$ \\
\hline $50 \%$ lean and $50 \%$ fatty & $86 \cdot 45$ & $8 \cdot 50$ & $1 \cdot 14$ & 0.94 & $1 \cdot 23$ & $9 \cdot 64$ \\
\hline Only fatty fish & $24 \cdot 79$ & $10 \cdot 27$ & $1 \cdot 60$ & $1 \cdot 56$ & $1 \cdot 74$ & $15 \cdot 41$ \\
\hline
\end{tabular}

MeHg, methylmercury; iPCB, seven indicator polychlorinated biphenyl ethers; dIPCB, dioxin-like PCB; PCDD/F, dioxins plus furans; totTEQ, total dioxin-like compounds; BW, body weight. 


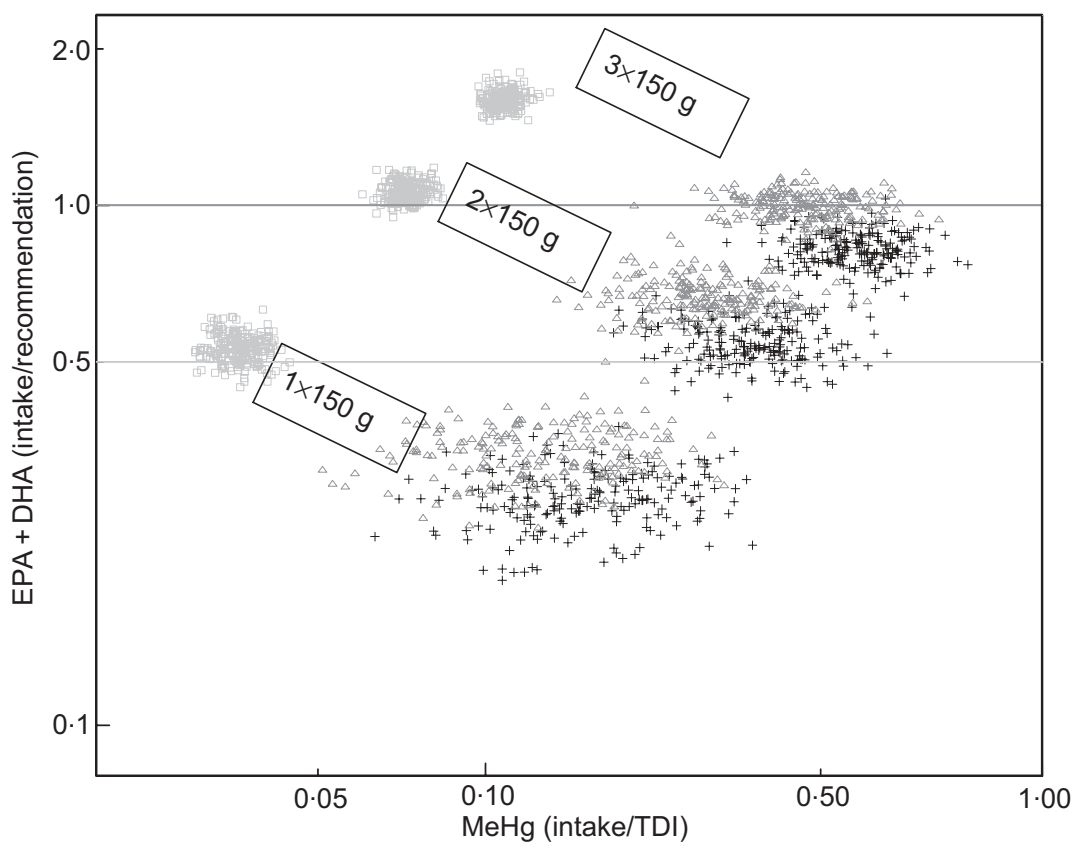

Fig. 2 Methylmercury (MeHg) intake divided by the tolerable daily intake (TDI; $228 \mathrm{ng} / \mathrm{kg}$ body weight (BW) per d) in relation to the intake of EPA plus DHA divided by the recommendation $(9 \cdot 7 \mathrm{mg} / \mathrm{kg} \mathrm{BW}$ per d) for three different fish consumption patterns (+, current consumption pattern; $\triangle, 50 \%$ lean and $50 \%$ fatty fish; $\square$, only fatty fish) and three different scenarios of consumption frequency (one, two or three times a portion of $150 \mathrm{~g}$ fish per week); note logarithmic scales

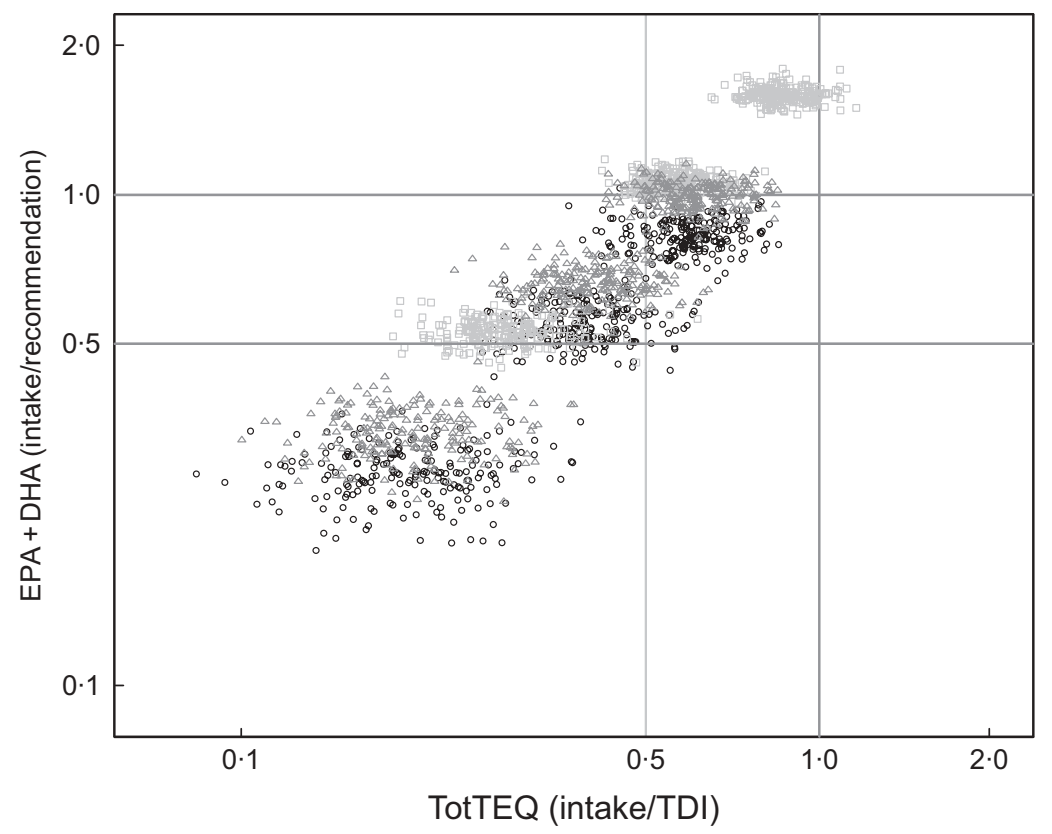

Fig. 3 Intake of total dioxin-like compounds (totTEQ) divided by the tolerable daily intake (TDI; 2 pg WHO-TEQ/kg body weight (BW) per d) in relation to the intake of EPA plus DHA divided by the recommendation $(9.7 \mathrm{mg} / \mathrm{kg} \mathrm{BW}$ per d) for three different fish consumption patterns $(O$, current consumption pattern; $\wedge, 50 \%$ lean and $50 \%$ fatty fish; $\square$, only fatty fish) and three different scenarios of consumption frequency (one, two or three times a portion of $150 \mathrm{~g}$ fish per week); note logarithmic scales

\section{Enriched margarine as extra dietary source of EPA and DHA}

Assuming that all consumers use $21 \cdot 2 \mathrm{~g}$ enriched margarine containing $7.5 \mathrm{mg} \mathrm{EPA}+\mathrm{DHA} / \mathrm{g}$ margarine daily will lead to a mean daily intake of $159 \mathrm{mg}$ EPA + DHA, being $23 \cdot 3 \%$ of the Belgian recommendation $(681 \mathrm{mg} / \mathrm{d})$. In Fig. 4 , scatter plots are shown for the different fish consumption scenarios with and without adding enriched margarine as a 

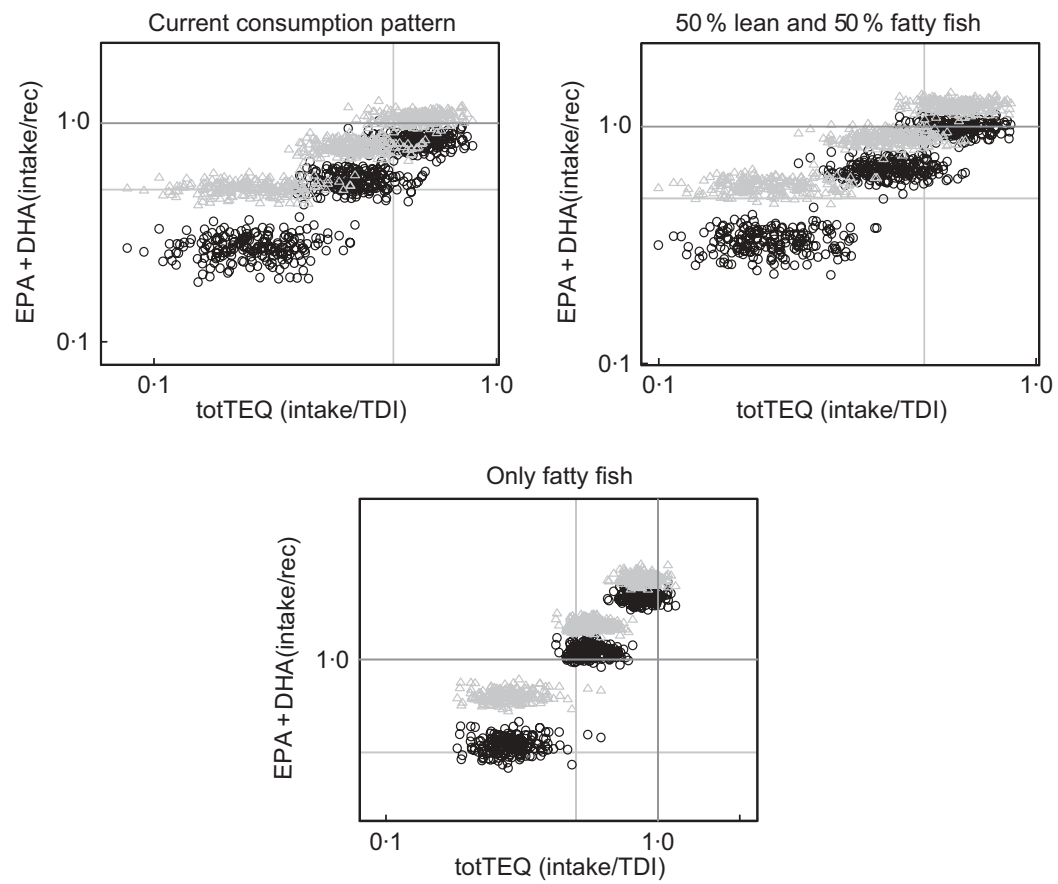

Fig. 4 Intake of total dioxin-like compounds (totTEQ) divided by the tolerable daily intake (TDI; 2 pg WHO-TEQ/kg body weight (BW) per d) in relation to the intake of EPA plus DHA divided by the recommendation (rec; $9.7 \mathrm{mg} / \mathrm{kg}$ BW per d) for three different fish consumption patterns (current consumption pattern, $50 \%$ lean and $50 \%$ fatty fish, only fatty fish) and three different scenarios of consumption frequency (one, two or three times a portion of $150 \mathrm{~g}$ fish per week), with $(\triangle)$ and without $(O)$ taking long-chain $n$-3 PUFA-enriched margarine into account; note logarithmic scales

source of LC $n$-3 PUFA, neglecting the contribution of margarine consumption to the intake of contaminants since no recent contamination data for margarine were available. Consuming enriched margarine will help to increase the $\mathrm{EPA}+\mathrm{DHA}$ intake. Nevertheless, the contribution is rather limited and margarine as the only source of LC $n$-3 PUFA would not be sufficient to reach the recommendation. A consumption scenario of $150 \mathrm{~g}$ lean fish and $150 \mathrm{~g}$ fatty fish per week combined with a daily consumption of LC $n-3$ PUFA-enriched margarine leads to an EPA + DHA intake close to the recommendation with a mean totTEQ intake below half of the TDI.

\section{Discussion}

The present results showed that the Belgian recommendation for EPA plus DHA can be reached through regular fish consumption, more specifically: (i) a combination of lean and fatty fish (on average $50 \%$ ) a minimum of three times a week; or (ii) fatty fish a minimum of twice a week. A consumption of fatty fish three times a week, however, leads to an intake of totTEQ close to the health-based guidance value, which is of potential toxicological concern because other food items, mainly of animal origin, also contribute to the daily totTEQ intake. Recent research assessed totTEQ intake via the total diet in three age groups on the basis of data from the Flemish
Environment and Health study. The median estimated intakes were $2 \cdot 24,2 \cdot 09$ and $1 \cdot 74 \mathrm{pg}$ TEQ $/ \mathrm{kg} \mathrm{BW}$ per $\mathrm{d}$ in respectively adolescents (14-15 years), mothers (18-44 years) and adults (50-65 years). It was found that seafood was the most important contributor, accounting for $25 \cdot 0$, 29.4 and $43.3 \%$ in the group of adolescents, mothers and adults, respectively. The other main contributors were, in order of importance, added fats, dairy products, and meat and meat products ${ }^{(36)}$. MeHg contamination does not seem to be an issue of toxicological concern, even in scenarios with elevated fish consumption frequencies. Hence, the consumption limits for fish determined in the present study are driven by the presence of dioxin-like contaminants, which was also concluded by Foran et $a l^{(20)}$ when performing an analysis of the risks and benefits related to salmon consumption.

Belgian adults currently do not consume seafood regularly ${ }^{(30)}$. The results of the most recent $\mathrm{BFCS}^{(34)}$ indicated a mean daily intake of $24 \mathrm{~g}$ seafood. Almost $70 \%$ of the population consumed less than $210 \mathrm{~g}$ seafood/ week $(30 \mathrm{~g} / \mathrm{d})$. Many obstacles at the consumer level exist to prevent people form consuming fish twice a week. Low perceived convenience, high price perception, and low liking of fish taste act as major barriers to increasing the consumption of fish in Belgium ${ }^{(37)}$. Therefore, it was worth investigating the role of EPA + DHA-enriched food items. The results showed that regular fish consumption (twice a week), including fatty fish species, in 
combination with regular consumption of EPA + DHAenriched margarine can be advised to safely increase the LC n-3 PUFA intake.

Apart from margarines, LC $n$-3 PUFA-enriched eggs are available on the Belgian market. A first brand stated that an enriched egg contains $110 \mathrm{mg} \mathrm{EPA}+\mathrm{DHA}$. The second reported a concentration of $125 \mathrm{mg}$ DHA/egg. The mean weight of a normal egg is assumed to be $60 \mathrm{~g}^{(35)}$. On the basis of the most recent $\mathrm{BFCS}^{(34)}$, it is known that Belgian adults consume on average $10.0 \mathrm{~g} \mathrm{egg} / \mathrm{d}$, i.e. one egg a week $^{(34)}$. Assuming that all eggs consumers would eat are $\mathrm{EPA}+\mathrm{DHA}-$ enriched eggs (110 mg EPA + DHA/egg), this would lead to an average daily intake of $18.3 \mathrm{mg} \mathrm{EPA}+$ DHA, being $2 \cdot 7 \%$ of the recommendation. To reach the recommendation of $681 \mathrm{mg} \mathrm{EPA}+\mathrm{DHA} / \mathrm{d}$, consumers should eat six eggs a day, increasing the cholesterol intake to $1483 \cdot 2 \mathrm{mg} / \mathrm{d}$ ( $412 \mathrm{mg}$ cholesterol/egg), whereas the Belgian recommendation states to reduce cholesterol intake to a maximum of $300 \mathrm{mg} / \mathrm{d}^{(7)}$. This indicates that the contribution of EPA + DHA-enriched eggs to the total intake is low, due to the rather low concentration of EPA + DHA in eggs and their limited consumption. Enriched eggs can help to increase the LC $n$-3 PUFA intake, but they cannot be advised as the only or major source to achieve the EPA plus DHA recommendation. Nevertheless, we must admit that the use of eggs in prepared food items such as cakes and pastries are not taken into consideration in this calculation, which leads to an underestimation.

According to literature, another option to increase the intake of EPA + DHA is through supplementation with DHA-rich micro-algae or fish oil. The use of such supplements as an alternative for fish will have disadvantages owing to the lack of other nutrients like protein and vitamin D, and minerals such as I and Se, that are abundantly present in fish. Moreover, fish is low in saturated fat and cholesterol and, therefore, regular replacement of meat and meat products by fish can help to reduce the intake of saturated $\mathrm{fat}^{(8,9)}$. Besides supplements, efforts are being made to enrich the EPA + DHA concentration of food items produced from terrestrial animals through adapted animal feeds and to develop a new generation of genetically modified plants with a modified fatty acid profile $^{(14,38,39)}$. Nevertheless, the availability of these food items containing EPA and DHA is still limited and their potential to increase the LC $n$-3 PUFA intake is still debated and most likely not sufficient ${ }^{(38)}$.

It is of interest to note that the EPA and DHA recommendation as formulated by the Belgian Health Council ${ }^{(7)}$ $(0 \cdot 3 \%$ of the total energy intake, estimated to be equal to $681 \mathrm{mg} / \mathrm{d})$ seems to be high compared with other international recommendations. In France, the recommendation for EPA and DHA is $0 \cdot 2 \%$ of the total energy intake, with a minimum of $0.05 \%$ contributed by $\mathrm{DHA}^{(40)}$, estimated to be equal to $500 \mathrm{mg} / \mathrm{d}$ for French men and $400 \mathrm{mg} / \mathrm{d}$ for French women. In Germany, a daily intake of $350 \mathrm{mg}$ LC $n$-3 PUFA is recommended ${ }^{(11)}$. In the UK, LC $n$-3 PUFA intake of minimal $450 \mathrm{mg} / \mathrm{d}$ is recommended $^{(41)}$. In the USA, the American Heart Association (AHA) formulated a dietary recommendation of $500 \mathrm{mg}$ $\mathrm{EPA}+\mathrm{DHA}$ daily for CVD risk reduction. For patients with documented $\mathrm{CHD}$, the AHA recommends $1 \mathrm{~g}$ $\mathrm{EPA}+\mathrm{DHA} / \mathrm{d}^{(14,42)}$. Application of such a lower recommendation (e.g. the French recommendation) for EPA + DHA would lead to the conclusion that (i) consumption of fish twice a week, varying between lean and fatty species (Figs 2 and 3), and (ii) combination of fish once a week with regular use of LC $n$-3 PUFA-enriched margarine (Fig. 4), would be sufficient to reach the $\mathrm{EPA}+\mathrm{DHA}$ intake recommendation.

With regard to the risk-benefit analysis executed in the present study, it should be emphasized that the cut-offs used for the evaluation of human health benefits and risks were determined taking into consideration different endpoints. Nevertheless, we attempted to describe the situation as accurately as possible by a simultaneous intake assessment of nutrients and contaminants. At this moment, no common metric exists to evaluate the benefits as well as the risks in one single step. Attempts have been undertaken to combine both assessments in terms of quality- or disabilityadjusted life years (QALY or DALY) ${ }^{(18,23,43)}$, but many uncertainties remain to be solved before a broad application of this procedure becomes possible. The largest uncertainties are associated with the dose-response relationships ${ }^{(18)}$. Moreover, the QALY investigations related to fish consumption did not take into account dioxin-like contaminants, but focused on $\mathrm{MeHg}$ only ${ }^{(18,23)}$.

The present study focused on the contaminants for which abundant concentration data are publicly available. Of course, other contaminants are also present in fish, e.g. $\mathrm{As}, \mathrm{Pb}$ and polybrominated diphenyl ethers. The rationale for focusing on $\mathrm{MeHg}$ was that fish is the most important dietary source of $\mathrm{Hg}$ in the human food chain. In the marine environment, inorganic $\mathrm{Hg}$ is to a high extent transformed to $\mathrm{MeHg}$, which further accumulates in the marine food chain and is very toxic to man ${ }^{(44,45)}$. The selection of dioxin-like compounds was motivated by the fact that fish has a higher concentration of dioxin-like compounds than other food items. Studies from Belgium and other European countries indicated fish as an important dietary source of dioxin-like compounds ${ }^{(46-51)}$.

In conclusion, the present study showed that the Belgian EPA plus DHA recommendation can be reached through regular consumption of fish, more specifically through a combination of lean and fatty fish (on average $50 \%$ of each) a minimum of three times a week or through consuming fatty fish twice a week. Consuming fatty fish more than twice a week, however, leads to totTEQ intake close to the TWI, which is of potential toxicological concern. In contrast, $\mathrm{MeHg}$ contamination does not seem to be an issue of toxicological concern in Belgium, even for heavy fish consumers. On the basis of these conclusions, clear dietary advice about fish 
consumption can be given to the Belgian population, in order to increase their LC $n$-3 PUFA intake without raising major toxicological concerns.

\section{Acknowledgements}

None of the authors had any conflict of interest. The Belgian Science Policy (SPSDII-project CP/02/56) and the Institute for the Promotion of Innovation through Science and Technology in Flanders (IWT-Vlaanderen, Brussels, Belgium) are acknowledged for financial support. S.D.H., J.V.C. and J.W. wrote the project proposal of the study. I.S. conducted the scenario analyses and wrote the article. F.V. provided statistical advice and helped in the interpretation of the results. All authors helped in interpreting the results and writing the manuscript. Nicky Van Thuyne and Peter Vanrolleghem (BIOMATH, Ghent University, Belgium) are acknowledged for support in the development of ProbIntake ${ }^{\mathrm{UG}}$.

\section{References}

1. Kris-Etherton PM, Harris WS \& Appel LJ (2002) Fish consumption, fish oil, omega- 3 fatty acids, and cardiovascular disease. Circulation 106, 2747-2757.

2. Sidhu KS (2003) Health benefits and potential risks related to consumption of fish or fish oil. Regulat Toxicol Pharmacol 38, 336-344.

3. Din JN, Newby DE \& Flapan AD (2004) Science, medicine, and the future - omega 3 fatty acids and cardiovascular disease - fishing for a natural treatment. BMJ 328, 30-35.

4. Ruxton CH, Reed SC, Simpson MJ \& Millington KJ (2004) The health benefits of omega-3 polyunsaturated fatty acids: a review of the evidence. J Hum Nutr Diet 17, 449-459.

5. Wang C, Harris WS, Chung M, Lichtenstein AH, Balk EM, Kupelnick B, Jordan HS \& Lau J (2006) n-3 Fatty acids from fish or fish-oil supplements, but not $\alpha$-linolenic acid, benefit cardiovascular disease outcomes in primary- and secondary-prevention studies: a systematic review. Am J Clin Nutr 84, 5-17.

6. Psota TL, Gebauer SK \& Kris-Etherton P (2006) Dietary omega-3 fatty acid intake and cardiovascular risk. $\mathrm{Am} \mathrm{J}$ Cardiol 98, 3-18.

7. Belgian Health Council (2006) Voedingsaanbevelingen voor België. Herziene versie 2006 (Nutritional Recommendations for Belgium. Revised version 2006). Brussels: Belgian Health Council; available at https://portal.health. fgov.be/pls/portal/

8. Sioen IA, Pynaert I, Matthys C, De Backer G, Van Camp J \& De Henauw S (2006) Dietary intakes and food sources of fatty acids for Belgian women, focused on $n-6$ and n-3 polyunsaturated fatty acids. Lipids 41, 415-422.

9. Sioen I, Matthys C, De Backer G, Van Camp J \& De Henauw S (2007) Importance of seafood as nutrient source in the diet of Belgian adolescents. J Hum Nutr Diet 20, 580-589.

10. Sioen I, Huybrechts I, Verbeke W, Van Camp J \& De Henauw S (2007) $n-6$ and $n$-3 PUFA intakes of pre-school children in Flanders, Belgium. Br J Nutr 98, 819-825.

11. Bauch A, Lindtner O, Mensink GB \& Niemann B (2006) Dietary intake and sources of long-chain $n-3$ PUFAs in German adults. Eur J Clin Nutr 60, 810-812.
12. Sontrop J \& Campbell MK (2006) Omega-3 polyunsaturated fatty acids and depression: a review of the evidence and a methodological critique. Prev Med 42, 4-13.

13. Deckelbaum RJ \& Akabas SR (2006) n-3 Fatty acids and cardiovascular disease: navigating toward recommendations. Am J Clin Nutr 84, 1-2.

14. Gebauer SK, Psota TL, Harris WS \& Kris-Etherton PM (2006) $n-3$ Fatty acid dietary recommendations and food sources to achieve essentiality and cardiovascular benefits. $\mathrm{Am} \mathrm{J}$ Clin Nutr 83, S1526-S1535.

15. Burreau S, Zebuhr Y, Broman D \& Ishaq R (2006) Biomagnification of PBDEs and PCBs in food webs from the Baltic Sea and the northern Atlantic Ocean. Sci Total Environ 366, 659-672.

16. EFSA (2004) Opinion of the scientific panel on contaminants in the food chain on a request from the Commission related to mercury and methylmercury in food. EFSA $J$ 34, 1-14.

17. World Health Organization (2007) Safety Evaluation of Certain Food Additives and Contaminants. Prepared by the Fifty-seventh Meeting of the Joint FAO/WHO Expert Committee on Food Additives. WHO Food Additives Series no. 48. Geneva: WHO; available at http://www.who.int/ ipcs/publications/jecfa/monographs/en/index.html

18. Cohen JT, Bellinger DC, Connor WE, Kris-Etherton PM, Lawrence RS, Savitz DA, Shaywitz BA, Teutsch SM \& Gray GM (2005) A quantitative risk-benefit analysis of changes in population fish consumption. Am J Prev Med 29, 325-334.

19. Sioen I, Van Camp J, Verdonck FAM, Van Thuyne N, Willems JL \& De Henauw SWJ (2007) How to use secondary data on seafood contamination for probabilistic exposure assessment purposes? Main problems and potential solutions. Hum Ecol Risk Assess 13, 632-657.

20. Foran JA, Good DH, Carpenter DO, Hamilton MC, Knuth BA \& Schwager SJ (2005) Quantitative analysis of the benefits and risks of consuming farmed and wild salmon. J Nutr 135, 2639-2643.

21. Foran JA, Carpenter DO, Hamilton MC, Knuth BA \& Schwager SJ (2005) Risk-based consumption advice for farmed Atlantic and wild Pacific salmon contaminated with dioxins and dioxin-like compounds. Environ Health Perspect 113, 552-556.

22. Huang X, Hites RA, Foran JA, Hamilton C, Knuth BA, Schwager SJ \& Carpenter DO (2006) Consumption advisories for salmon based on risk of cancer and noncancer health effects. Environ Res 101, 263-274.

23. Ponce RA, Bartell SM, Wong EY, LaFlamme D, Carrington C, Lee RC, Patrick DL, Faustman EM \& Bolger M (2000) Use of quality-adjusted life year weights with dose-response models for public health decisions: a case study of the risks and benefits of fish consumption. Risk Anal 20, 529-542

24. Levenson CW \& Axelrad DM (2006) Too much of a good thing? Update on fish consumption and mercury exposure. Nutr Rev 64, 139-145.

25. Sioen I, De Henauw S, Verdonck F, Van Thuyne N \& Van Camp J (2007) Development of a nutrient database and distributions for use in a probabilistic risk-benefit analysis of human seafood consumption. J Food Compost Anal 20, 662-670.

26. Kiviranta H, Vartiainen $T$, Parmanne R, Hallikainen A \& Koistinen J (2003) PCDD/Fs and PCBs in Baltic herring during the 1990s. Chemosphere 50, 1201-1216.

27. Roots O \& Zitko V (2004) Chlorinated dibenzo-p-dioxins and dibenzofurans in the Baltic herring and sprat of Estonian coastal waters. Environ Sci Pollut Res Int 11, 186-193.

28. Gallani B \& Boix A (2004) Dioxins and PCBs in Food and Feed: Data Available to the European Commission. EUR 21093 EN. Brussels: European Commission. 
29. European Commission (2006) Commission Regulation (EC) No 1881/2006 of 19 December 2006 setting maximum levels for certain contaminants in foodstuffs. Brussels: European Commission.

30. Honkanen P \& Brunsø K (2007) On the average European fish consumption is below recommended levels. Deliverable 4, Project 2.1, SEAFOODplus. http://www.seafoodplus.org/ Europen_fish_consumption.411.0.html (accessed January 2007).

31. Kornitzer M \& Dramaix M (1989) The Belgian Interuniversity Research on Nutrition and Health (BIRNH): general introduction. For the BIRNH Study Group. Acta Cardiol 44, 89-99.

32. De Backer G (1984) Nutrition and health: an interuniversity study. Regional differences in dietary habits, coronary risk factors and mortality rates in Belgium. I. Design and methodology. Acta Cardiol 39, 285-292.

33. R Development Core Team (2006) $R$ : A Language and Environment for Statistical Computing. Vienna: R Foundation for Statistical Computing.

34. De Vriese SR, Huybrechts I, Moreau M \& Van Oyen H (2006) De Belgische Voedselconsumptiepeiling (The Belgian Food Consumption Survey). IPH/EPI Reports no. 2006-016. Brussels: Scientific Health Institute, Department of Epidemiology; available at http://www.iph.fgov.be/epidemio/ epinl/index $5 . h t m$

35. Belgian Health Council (2005) Maten en gewichten. Handleiding voor gestandaardiseerde kwantificering van voedingsmiddelen in België (Measures and Weights. Manual for Standardised Quantification of Food Items in Belgium). HGR 6545-2. Brussels: Belgian Health Council; available at http://www.health.fgov.be/CSH_HGR

36. Bilau M, Matthys C, Baeyens W et al. (2007) Dietary exposure to dioxin-like compounds in three age groups: results from the Flemish Environment and Health study. Chemosphere (Epublication ahead of print version).

37. Olsen SO, Scholderer J, Brunsø K \& Verbeke W (2007) Exploring the relationship between convenience and fish consumption: a cross-cultural study. Appetite 49, 84-91.

38. De Henauw S, Van Camp J, Sturtewagen G, Matthys C, Bilau M, Warnants N, Raes K, Van Oeckel M \& De Smet S (2007) Simulated changes in fatty acid intake in humans through $n-3$ fatty acid enrichment of foods from animal origin. J Sci Food Agric 87, 200-211.

39. Kinney AJ (2006) Metabolic engineering in plants for human health and nutrition. Curr Opin Biotechnol 17, 130-138.
40. Legrand P, Bourre JM, Descomps B, Durand G \& Renaud S (2001) Lipides. In Apports nutritionnels conseillés pour la population française, 3rd ed., pp. 63-82 [A Martin, editor]. Paris: Tec \& Doc.

41. Scientific Advisory Committee on Nutrition/Committee on Toxicity (2004) Advice on Fish Consumption: Benefits and Risks. Norwich: TSO.

42. Kris-Etherton PM, Harris WS \& Appel LJ (2003) Omega-3 fatty acids and cardiovascular disease - new recommendations from the American Heart Association. Arterioscler Thromb Vasc Biol 23, 151-152.

43. van Kreijl CF \& Knaap AGAC (2006) Our Food, Our Health - Healthy Diet and Safe Food in The Netherlands. Bilthoven: RIVM.

44. Plessi M, Bertelli D \& Monzani J (2001) Mercury and selenium content in selected seafood. J Food Compost Anal 14, 461-467.

45. Storelli MM, Giacominelli-Stuffler R, Storelli A \& Marcotrigiano GO (2003) Polychlorinated biphenyls in seafood: contamination levels and human dietary exposure. Food Chem 82, 491-496.

46. Vrijens B, De Henauw S, Dewettinck K, Talloen W, Goeyens L, De Backer G \& Willems GL (2002) Probabilistic intake assessment and body burden estimation of dioxinlike substances in background conditions and during a short food contamination episode. Food Addit Contam 19, 687-700.

47. Baars AJ, Bakker MI, Baumann RA et al. (2004) Dioxins, dioxin-like PCBs and non-dioxin-like PCBs in foodstuffs: occurrence and dietary intake in The Netherlands. Toxicol Lett 151, 51-61.

48. Darnerud PO, Atuma S, Aune M, Bjerselius R, Glynn A, Grawe KP \& Becker W (2006) Dietary intake estimations of organohalogen contaminants (dioxins, PCB, PBDE and chlorinated pesticides, e.g. DDT) based on Swedish market basket data. Food Chem Toxicol 44, 1597-1606.

49. Taioli E, Marabelli R, Scortichini G, Migliorati G, Pedotti P, Cigliano A \& Caporale V (2005) Human exposure to dioxins through diet in Italy. Chemosphere $\mathbf{6 1}$, $1672-1676$.

50. Fattore E, Fanelli R, Turrini A \& di Domenico A (2006) Current dietary exposure to polychlorodibenzo- $p$-dioxins, polychlorodibenzofurans, and dioxin-like polychlorobiphenyls in Italy. Mol Nutr Food Res 50, 915-921.

51. Kiviranta H, Ovaskainen ML \& Vartiainen T (2004) Market basket study on dietary intake of PCDD/Fs, PCBs, and PBDEs in Finland. Environ Int 30, 923-932. 